\title{
Study on Mechanical Properties of Multiwalled Carbon Nanotubes Reinforced with Aluminium 2024 Matrix Composites with Nickel Coating
}

\author{
Muzakkir Ahmed Khan"1, Dr. P Vijaya Kumar², Puneeth P², Meghashree K A ${ }^{3}$ \\ ${ }^{* 1}$ Research Scholar, Department of Mechanical Engineering, UVCE, Bangalore, Karnataka, India \\ ${ }^{2}$ Professor, Department of Mechanical Engineering, UVCE, Bangalore, Karnataka, India \\ 2,3P.G. Scholar, Department of Mechanical Engineering, UVCE, Bangalore, Karnataka, India
}

\begin{abstract}
Various metal matrix composites (MMCs) are widely used in the automotive, aerospace and electrical industries due to their capability and flexibility in improving the mechanical, thermal and electrical properties of a component. However, current manufacturing technologies may suffer from insufficient process stability, reliability and inadequate economic efficiency and may not be able to satisfy the increasing demands placed on MMCs. So CNT based Aluminium based metal matrix composites (MMCs) has been a better choice for the industrial applications due to their Inherent properties like ductile, highly conductive, lightweight and have a high strength to weight ratio. In this study, Multiwall carbon nanotube(MWCNT) which is emerged as a excellent reinforcement material and 2024 aluminium alloy being a matrix material were selected for the development of MMC's. Stir casting process being a low cost casting technology which has potential to produce MMCs having agility to large scale production with great manufacturing flexibility, quality and high efficiency. In this work, The experimental investigation of CNT reinforced 2024 Aluminium MMCs under Stir casting technique were explored. Casted samples were prepared with different wt $\%$ of reinforcements(i.e., 0.5 $\%, 1.0 \%, 1.5 \%$ \& $2 \%$ CNT's with 40micron nickel coating on the surface using electro-less plating process) and compared with unreinforced aluminium specimens for the investigation of mechanical properties such as Tensile, Compressive, and Hardness has been evaluated as per ASTM standard.
\end{abstract}

Keywords: Stir casting process, Al 2024, Multiwall carbon nanotube (MWCNT), nickel coating, Ultimate Tensile Strength, Compression strength, hardness.

\section{INTRODUCTION}

The current investigation is carried out on MWCNT reinforced with Aluminium 2024 MMCs under Stir casting technique.

Aluminium matrix composites (AMCs) with their enhanced strength, improved stiffness, reduced density, improved abrasion and wear resistance offer better alternative to existing materials used for structural, non-structural and functional applications. Commonly used reinforcement in AMCs are of micro level, however technological advancement in nano sciences makes it possible to use nano sized reinforcement in metal matrix composites and these are termed as Metal Matrix Nano Composites (MMNCs). "Nano composites" were proposed by Choi and Awaji, a new material design concept where in second phase nano particles dispersed in matrix to enhance various properties of composite materials. In 
MMNCs, the reinforcement is in the nanometer range $(109 \mathrm{~m})$ i.e. less than $100 \mathrm{~nm}$ which has interaction at Interface due to its increased surface area, this leads to superior material properties. Nano sized reinforcements can significantly improve mechanical strength, creep resistance at elevated temperature, better machinability and higher fatigue life without affecting ductility. Improvement in the properties of MMCs is attributed to the hardening mechanism, fine particle size, and uniform distribution, inter particle spacing and thermal stability at high temperature. Hybrid composites can have engineering combination of two or more forms of reinforcement like fibers, short fibers, particulates, whiskers and nanotubes. It can have different materials as reinforcement like (SiC, Al2O3), (Graphite, SiC) and (Graphite, Al2O3), etc. e.g. Car engine block in which graphite and alumina are used in the form of particulates [8-10]. Hybrid metal matrix composites shows improved mechanical properties due to reduction in meniscus penetration defect and reduced formation of intermetallic component at interfaces because of increased interfacial area.

Aluminium 2024 is a precipitation hardening aluminium alloy, containing magnesium and silicon as its major alloying elements. Al2024 alloys have been widely used as structural materials in aeronautical industries due to their attractive comprehensive properties, such as low density, high strength, ductility, toughness and resistance to fatigue. Chunfeng Deng has found that carbon nanotube offers a kind of Nano size reinforcement that is light weight, a hollow core, has immense aspect ratio and has remarkable mechanical electrical and thermal properties. The investigators have used $2024 \mathrm{Al}$ matrix composites reinforced with $1 \mathrm{wt} \%$ CNT's which was fabricated by cold isotactic pressing followed by hot extrusion techniques.
The MWCNTs were Ni plated in some cases for better wettability with the matrix which resulted in mechanical property enhancement with only $0.67 \mathrm{wt}$ $\% C N T$ addition. The study showed that the number of cycles to failure under fatigue decreases with increasing CNT content; the reason being the presence of voids at the CNT matrix interface, making the reinforcement weaker. The main issue for better performance of the composite is the dispersion and reinforcement of the MWCNTs. In this present investigation the effect of Nickel coating with Aluminium will be studied \& evaluated the Mechanical properties as per ASTM standard.

\section{EXPERIMENT METHODOLOGY}

Al 2024: with density $2.78 \mathrm{~g} / \mathrm{cm} 3$, tensile strength 483 $\mathrm{MPa}$ (T4 condition) and modulus of elasticity 73.1 GPa was used as a matrix material. 2024 is a precipitation hardened aluminum alloy, containing magnesium and silicon as its major alloying elements. It has significant applications in aircraft, marine and automobile industries due to its good castability and corrosion resistance.

MWCNT: The MWCNT's (Multi-walled carbon nanotubes) were used as the reinforcement material and procured from United Nanotech Innovations PVT Ltd., Bangalore, India. Nickel plating was done by electroless process over the composite surface in peenya industrial area, Bangalore.

FLY ASH: Fly ash is produced by coal-fired electric and steam generating plants. Typically, coal is pulverized and brown with air into the boiler's combustion chamber where it immediately ignites, generating heat and producing a molten mineral residue. 


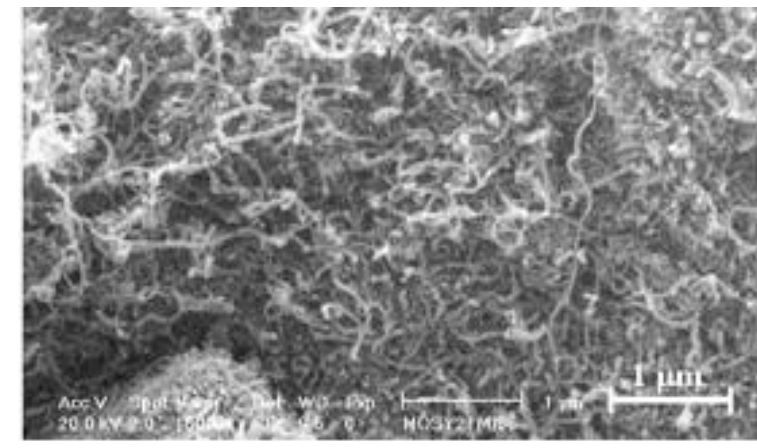

Fig 1.1: SEM Image of MWCNT

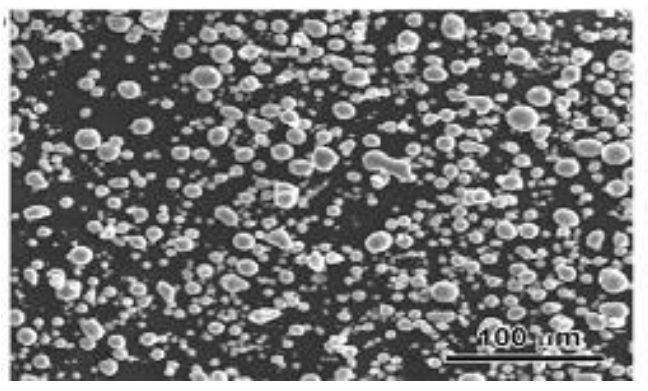

Fig 1.2: SEM Image of 2024 Aluminium Powder

Purification of MWCNTs is done using concentrated nitric acid for 0-25 hour and washing of MWCNTs with de-ionized water and drying period of $120 \mathrm{hrs}$. The Fabrication of Composite specimens using CNTs with different weight contents $(0.5 \%, 1 \%, 1.5 \%$, \& 2\%) reinforced with Aluminum2024 powder is done by using Stir casting process.

\section{Stir casting:}

In a stir casting process, the reinforcing phases are distributed into molten matrix by mechanical stirring. Mechanical stirring in the furnace is a key element of this process, a major concern associated with the stir casting process is the segregation of reinforcing particles which is caused by the surfacing or settling of the reinforcement particles during the melting and casting processes.

The final distribution of the particles in the solid depends on material properties and process parameters such as the wetting condition of the particles with the melt, strength of mixing, relative density, and rate of solidification. The distribution of the particles in the molten matrix depends on the geometry of the mechanical stirrer, stirring parameters, placement of the mechanical stirrer in the melt, melting temperature, and the characteristics of the particles added. An interesting recent development in stir casting is a two-step mixing process. In this process, the matrix material is heated to above its liquids temperature so that the metal is totally melted. The melt is then cooled down to a temperature between the liquids and solidus points and kept in a semi-solid state. At this stage, the preheated particles are added and mixed. The slurry is again heated to a fully liquid state and mixed thoroughly. This twostep mixing process has been used in the fabrication of aluminium. Among all the well-established metal matrix composite fabrication methods, stir casting is the most economical.

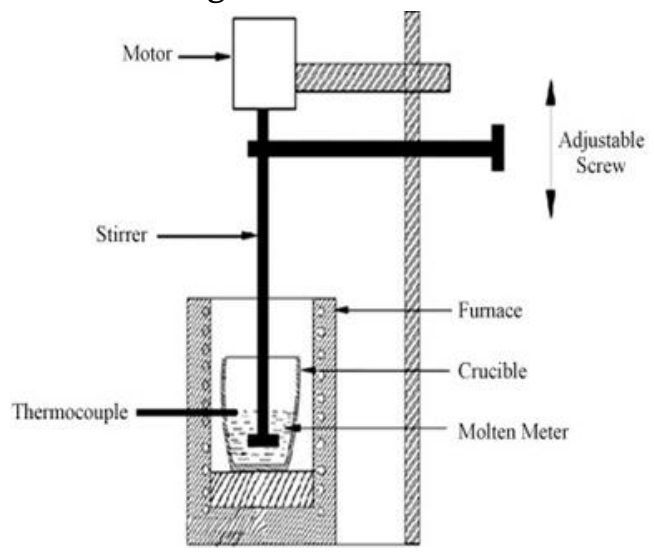

Fig. 1.3: Stir casting process

\section{METHODS}

Al2024 and multiwall carbon nano tubes (20-30 nm) were properly mixed for composition using stir casting process with a Stirrer speed of 300rpm was used to mix the MWCNT added for casting process.

\section{PREPARATION OF COMPOSITE SPECIMENS}

The CNT powder was initially purified to remove the impurities like graphite, amorphous carbon etc. by adding concentrated Nitric acid, filtering and washing with de-ionized water followed by drying at $1200 \mathrm{C}$. 
In stir casting process, MWNT of $0 \mathrm{wt} \% .0 .5 \mathrm{wt} . \%, 1$ wt. \%, 1.5 wt. $\%, 2$ wt. \% was mixed with Al2024 for $20 \mathrm{~min}$ at $300 \mathrm{rpm}$ to get uniform mixing in the crucible. The mixture of a particular weight percentage of MWCNT and Al2024 was moulded in the pattern.

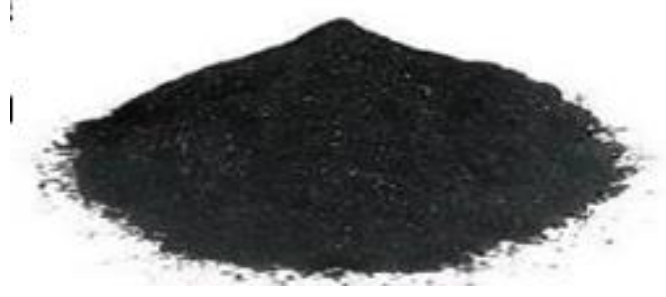

Fig. 1.4: CNT

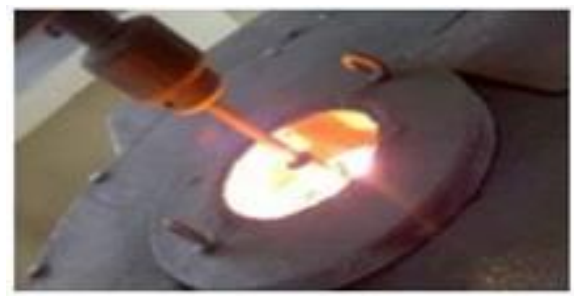

Fig. 1.5: Stir casting

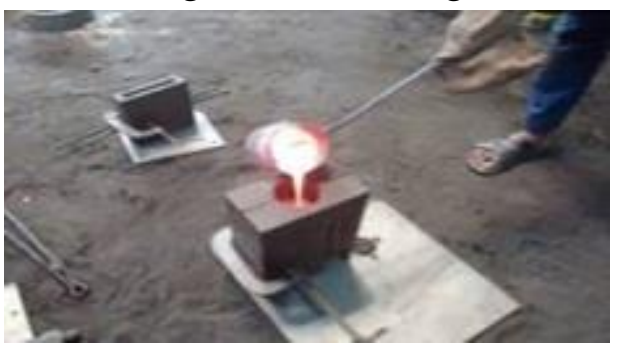

Fig. 1.6: Moulding.

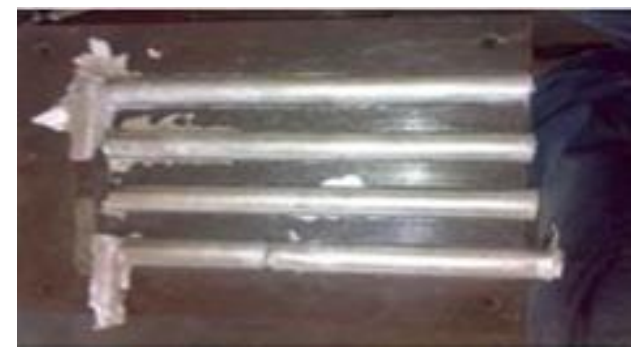

Fig. 1.7: Final Castings

Fig, 1.5, 1.6 and 1.7. Liquid melt technique was used to fabricate the composite materials in which the $\mathrm{CNT}$ reinforcing materials were introduced into the molten metal pool through a vortex generated in the melt crucible by the use of a stainless steel stirrer which is rotating in the speed of 300rpm. The resulting mixture was tilt poured into the pre-heated permanent metallic moulds. Using CNC lathe as cast specimen are machined to required dimensions from the cylindrical bar castings as per ASTM standard. Thus about specimen undergoes the process of nickel plating which takes in different stages which involves immersion in various alkaline bath to obtain clean surface, then they are dipped in nickel salt solution for the define amount of time as calculated based on the weight of the specimen dipped in it to obtain the uniform deposition of 40micron of nickel on the surface.

\section{EXPERIMENTAL PROCEDURE}

\section{Tensile Test}

The major static tests carried out are tensile tests, compression tests, Impact tests and Hardness tests. The details of the tests carried out are listed below:

Specimens are machined as per ASTM B557 test Standards to test for its tensile strength, the specific gauge length was taken as $62.5 \mathrm{~mm}$, grip distance as $115 \mathrm{~mm}$ and gauge diameter as $12.5 \mathrm{~mm}$, Tensile tests are carried with the speed of cross head taken to be constant at $5 \mathrm{~mm} / \mathrm{min}$ in a tensometer of $20 \mathrm{k} \mathrm{N}$ range.

The tensile testing is carried out by applying longitudinal or axial load at a specific extension rate to a standard tensile specimen with known dimensions (gauge length and cross sectional area perpendicular to the load direction) till failure. The applied tensile load and extension are recorded during the test for the calculation of stress and strain. A range of universal standards. Provided by Professional societies such as American Society of Testing and Materials (ASTM), British standard, JIS standard and DIN standard provides testing are selected based on preferential uses. Each standard may contain a variety of test standards suitable for different materials, dimensions and fabrication history. For instance, 
ASTM E8: is a standard test method for tension testing of metallic materials and ASTM B557 is standard test methods of tension testing wrought and cast aluminium and magnesium alloy products.

The in-detailed procedure for carrying out the tensile tests to evaluate the tensile characteristics are mentioned below:

\section{Procedure}

- The load pointer is set at zero by adjusting the initial setting knob.

- The dial gauge is fixed and the specimen for measuring elongation of small amounts.

- Measuring the diameter of the test piece by Vernier calliper at least at three places and determine mean value also mark the gauge length.

- Now the specimen is gripped between upper and middle cross head jaws of the $\mathrm{m} / \mathrm{c}$.

- Set the automatic graph recording system.

- Start the $\mathrm{m} / \mathrm{c}$ and take the reading.

- The specimen is loaded gradually and the elongation is noted until the specimen breaks.

- Ultimate tensile strength and percentage of elongation are calculated.

The photograph of the tensometer used in the current work is given below in figure -1.1 .

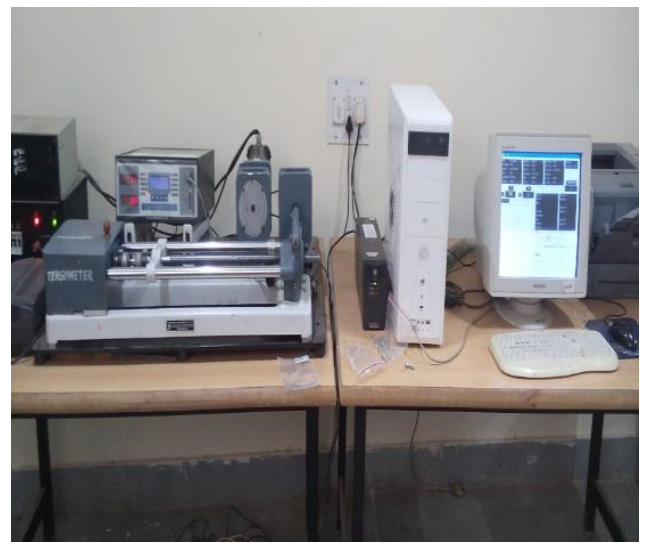

Figure -1.8 Tensometer used in the current work
Table 1.1: The specification of Tensometer

\begin{tabular}{|l|l|}
\hline \multicolumn{1}{|c|}{ Specification } & Tensile \\
\hline Component & Dumbbells shaped \\
\hline Cross-section & Round type \\
\hline High load limit & $20050 \mathrm{~N}$ \\
\hline Test speed & $0.5 \mathrm{~mm} / \mathrm{min}$ \\
\hline Proof stress & $0.2 \%$ \\
\hline
\end{tabular}

\section{Compression test}

The compression tests are carried out as per ASTM D3410 standards, the specimen size chosen for compression tests are of diameter $15 \mathrm{~mm}$ and length $20 \mathrm{~mm}$, The tests are carried out on INSTRON Universal test machine with slow movement of cross head. A Universal Testing machine, also known as a universal tester, materials testing machine is used to test the compressive strength of materials. The system is ideal since it replaces transmission of load through levers and knife edges, which are prone to wear and damage due to shock on rupture of test pieces. Load is applied by a hydrostatically lubricated ram. Main cylinder pressure is transmitted to the cylinder of the pendulum dynamometer system housed in the control panel. The in-detailed procedure for carrying out the compression tests to evaluate the compression strength are mentioned as follows:

\section{Procedure}

- The specimen of standard dimensions is located between the compression grips that are adjusted manually

- Constantly increasing load is applied to the specimen which is being constantly monitored

- The load at which fracture occurs is noted down and the percentage increase in area is computed.

- The percentage decrease in length is further calculated.

Finally, the ultimate compression strength for all the composite specimens are computed and subsequently tabulated. 


\section{Hardness test}

Brinell hardness test is carried out to determine the hardness of the specimens synthesized, it is very important to ensure that the material resists indentation and wear against abrasive particles when used for potential applications in automobile, aerospace and marine industry, Thus in current work, the specimens are tested for hardness using a NEWAGE brinell hardness testing machine.

The tests are carried out as per ASTM E10 Standards by making use of a $10 \mathrm{~mm}$ diameter hardened steel ball with a 500 kilogram force load applied for a period of 30 seconds. Out of all the other tests, deepest and widest indentations are obtained by brinell hardness testing methods which effectively gives the account for average hardness of the material over a wide surface of the material. The schematic of a brinell hardness test specimen is as shown in figure 1.9 .

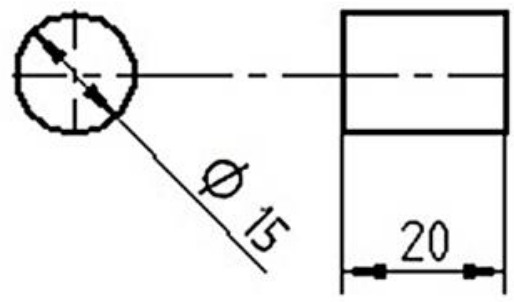

Figure - 1.9 Schematic of Brinell hardness Test Specimen

The specimen considered for the present work is having a diameter of $15 \mathrm{~mm}$ and a length of $20 \mathrm{~mm}$ with the surface of the specimen subjected to indentation.

\section{RESULT}

\section{Tensile Test}

Tensile is a maximum stress that a material can withstand while being stretched or pulled before failing or fracturing. Thus the overall inferences of the tensile test results are given in the current section.
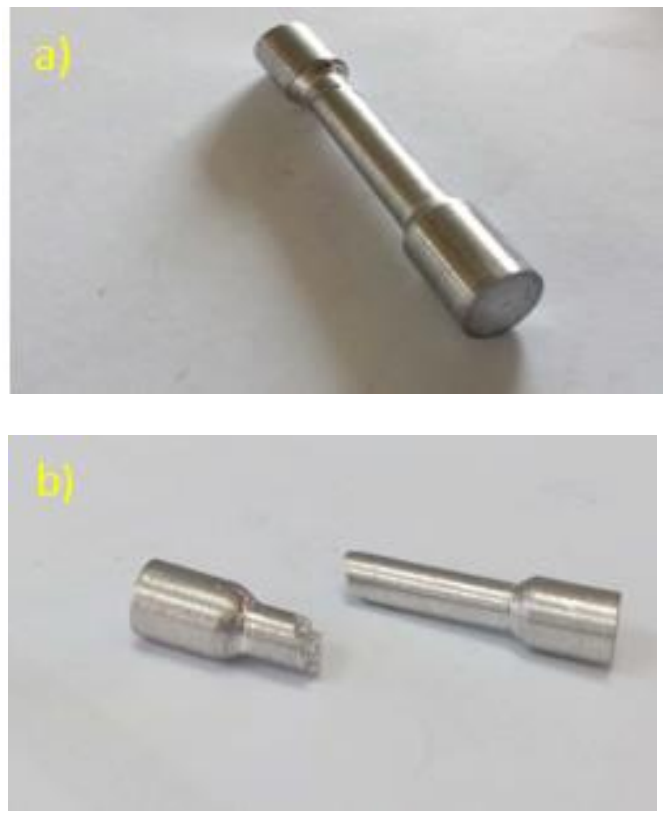

Figure 1.11 Tensile Test Specimen (a) before and (b) after the test.

The tensile strength results of Al-2024 alloy reinforced with Fly Ash and MWCNT is as show in graph (Fig 1.12) and table 1.2. It also gives the variation of tensile strength with percentage variation in Fly Ash and MWCNT in comparison with the base alloy (141.9 $\mathrm{MPa})$.

Table -1.2 Tensile Strength Results

\begin{tabular}{|c|c|c|c|c|c|}
\hline Sl.no & $\begin{array}{c}\text { Specimen } \\
\text { Designation }\end{array}$ & $\begin{array}{c}\text { AA } \\
\mathbf{2 0 2 4}\end{array}$ & MWCNT & $\begin{array}{c}\text { Fly } \\
\text { Ash }\end{array}$ & $\begin{array}{c}\text { Tensile } \\
\text { Strength } \\
\text { (MPA) }\end{array}$ \\
\hline 1. & AM1F4 & 95 & 1 & 4 & 164.5 \\
\hline 2. & AM1F6 & 93 & 1 & 6 & 173.7 \\
\hline 3. & AM1F8 & 91 & 1 & 8 & 185.2 \\
\hline 4. & AM1.5F4 & 94.5 & 1.5 & 4 & 192.6 \\
\hline 5. & AM1.5F6 & 92.5 & 1.5 & 6 & 201.4 \\
\hline 6. & AM1.5F8 & 90.5 & 1.5 & 8 & 210.9 \\
\hline 7. & AM2F4 & 94 & 2 & 4 & 218.8 \\
\hline 8. & AM2F6 & 92 & 2 & 6 & 225.3 \\
\hline 9. & AM2F8 & 90 & 2 & 8 & 234.1 \\
\hline
\end{tabular}




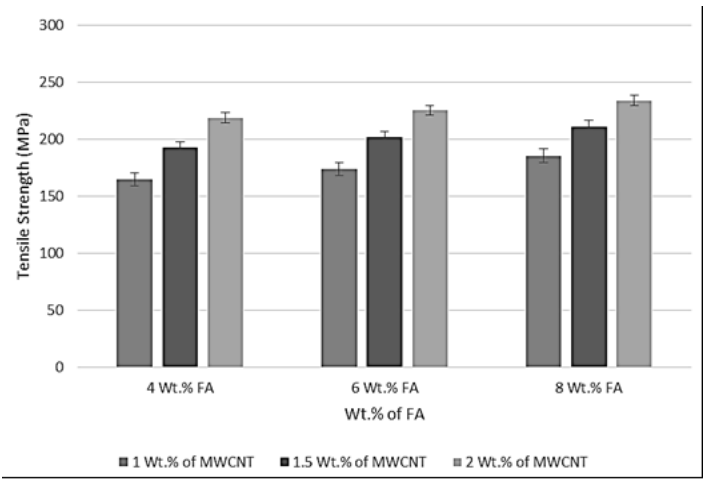

Fig - 1.12 Tensile Strength for different specimens

\section{Compression Strength}

The compression strength results of Al-2024 alloy reinforced with Fly Ash and MWCNT is as show in graph (Fig 1.13) and table 1.3. It also gives the variation of compression strength with percentage variation in Fly Ash and MWCNT.

Table - 1.3 Compression Strength Results.

\begin{tabular}{|c|c|c|c|c|c|}
\hline $\begin{array}{c}\text { Sl. } \\
\text { no }\end{array}$ & $\begin{array}{c}\text { Specimen } \\
\text { Designatio } \\
\mathbf{n}\end{array}$ & $\begin{array}{c}\text { AA } \\
\mathbf{2 0 2} \\
\mathbf{4}\end{array}$ & $\begin{array}{c}\text { MW } \\
\text { CNT }\end{array}$ & $\begin{array}{c}\text { Fly } \\
\text { As } \\
\mathbf{h}\end{array}$ & $\begin{array}{c}\text { Compressio } \\
\text { n Strength } \\
\text { (MPA) }\end{array}$ \\
\hline 1. & AM1F4 & 95 & 1 & 4 & 636.5 \\
\hline 2. & AM1F6 & 93 & 1 & 6 & 648.2 \\
\hline 3. & AM1F8 & 91 & 1 & 8 & 660.4 \\
\hline 4. & AM1.5F4 & 94.5 & 1.5 & 4 & 672.3 \\
\hline 5. & AM1.5F6 & 92.5 & 1.5 & 6 & 683.9 \\
\hline 6. & AM1.5F8 & 90.5 & 1.5 & 8 & 695.6 \\
\hline 7. & AM2F4 & 94 & 2 & 4 & 718.8 \\
\hline 8. & AM2F6 & 92 & 2 & 6 & 735.7 \\
\hline 9. & AM2F8 & 90 & 2 & 8 & 752.1 \\
\hline
\end{tabular}

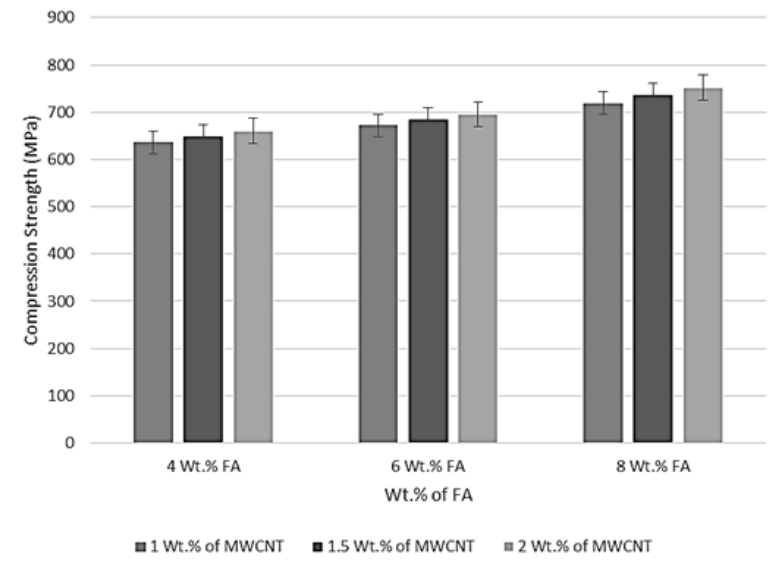

Fig - 1.13 Compression Strength for different specimens

\section{Hardness Test Results}

The hardness test results of Al-2024 alloy reinforced with Fly Ash and MWCNT is as show in graph (Fig 1.14) and table 1.4. It also gives the variation of Hardness with percentage variation in Fly Ash and MWCNT in comparison with the base alloy (52.9 BHN).

The increase in hardness is majorly due to the inclusion of reinforcements, especially MWNCT which imparts the necessary properties due to the phenomena of micro-coring and segregation in the Aluminium AA 2024 Matrix Phase.

Table -1.4 Results of Hardness Test

\begin{tabular}{|c|c|c|c|c|c|}
\hline $\begin{array}{c}\text { Sl.n } \\
\text { o }\end{array}$ & $\begin{array}{c}\text { Specimen } \\
\text { Designatio } \\
\mathbf{n}\end{array}$ & $\begin{array}{c}\text { AA } \\
\mathbf{2 0 2} \\
\mathbf{4}\end{array}$ & $\begin{array}{c}\text { MWCN } \\
\text { T }\end{array}$ & $\begin{array}{c}\text { Fly } \\
\text { As } \\
\text { h }\end{array}$ & $\begin{array}{c}\text { Hardnes } \\
\text { s }\end{array}$ \\
\hline 1. & AM1F4 & 95 & 1 & 4 & 63.2 \\
\hline 2. & AM1F6 & 93 & 1 & 6 & 64.5 \\
\hline 3. & AM1F8 & 91 & 1 & 8 & 65.3 \\
\hline 4. & AM1.5F4 & 94.5 & 1.5 & 4 & 72.4 \\
\hline 5. & AM1.5F6 & 92.5 & 1.5 & 6 & 81.7 \\
\hline 6. & AM1.5F8 & 90.5 & 1.5 & 8 & 89.6 \\
\hline 7. & AM2F4 & 94 & 2 & 4 & 93.9 \\
\hline
\end{tabular}




\begin{tabular}{|c|c|c|c|c|c|}
\hline 8. & AM2F6 & 92 & 2 & 6 & 95.8 \\
\hline 9. & AM2F8 & 90 & 2 & 8 & 98.1 \\
\hline
\end{tabular}

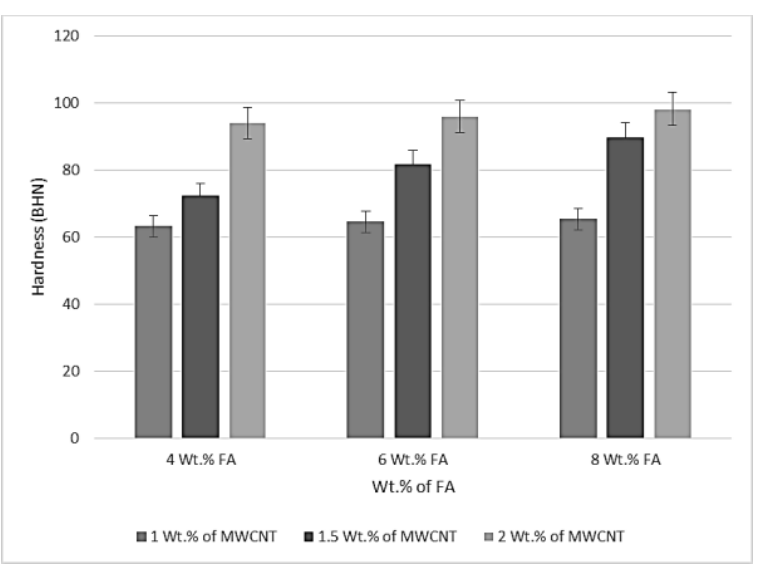

Fig - 1.14 Results of Hardness for different specimens

\section{DISCUSSION \& CONCLUSION}

- The results of Tensile and Compression tests clearly gives an inference that the tensile and compression strength of the composites increase with the increase in weight percentage of reinforcements in the matrix phase thereby increasing the strength characteristics of the composite specimens.

- Further, the composite specimens exhibit an increase in the strength properties when the weight percentage of MWCNT increases from 1 weight percent to 2 weight percent in intermittent steps of 0.5 weight percent.

- The results of Hardness clearly gives an inference that the absorption capability of the composites increase with the increase in weight percentage of reinforcements in the matrix phase, thereby increasing the strength characteristics of the composite specimens.

\section{REFERENCES}

[1] Miracle DB, Donaldson SL. Introduction to composites, ASM Handbook on Composites, vol. 21. Materials Part: ASM International; 2001. pp. 3-17.
[2] Rittner M. Metal matrix composites in the 21st century: markets and opportunities. Norwalk, CT: BCC, Inc.; 2000.

[3] Clyne TW, Withers PJ. An introduction to metal matrix composites, Paperback Pub. In 1994 ed. Cambridge: Cambridge University Press; 1993.

[4] Evans A, Marchi CS, Mortensen A. Metal matrix composites in industry: an introduction and a survey. Dordrecht, Nether-lands: Kluwer Academic Publishers; 2003.

[5] Chawla N, Andres C, Jones Wallison JE. Effect of $\mathrm{SiC}$ volume fraction and particle size on the fatigue resistance of a $2080 \mathrm{Al} / \mathrm{SiCp}$ composite. Met \& Mat Trans 1998; 29A:284354.

[6] Kouzeli M, Mortensen A. Size dependent strengthening in particle reinforced aluminium. Acta Mater 2002; 50:39-51.

[7] Lewandowski JJ, Liu C. Effects of matrix microstructure and particle distribution on fracture of an aluminium metal matrix composite. Mat. Sci. Engg. A 1989; 107:24155.

[8] Davis JR, editor. Metals handbook. Desk ed. Materials Park, OH: ASM, International; 1998.

[9] Shercliff HR, Ashby MF. Design with metal matrix composites. Mat. Sci. Tech. 1994; 10:443-51.

[10] A.Wang \& H.J.Rack, “Transition wear behaviour of $\mathrm{SiC}$-particulate and $\mathrm{SiC}$ whisker reinforced $7091 \mathrm{Al}$ metal matrix composites", Journal of Material Science and Engineering A, Vol. 147, 2018, pp 211-224.

[11] T. Alpas, J. Zhang, "Effect of microstructure (particulate size and volume fraction) and counter face material on the sliding wear resistance of particulate-reinforced aluminium matrix composites", Metall. Mater. Trans. A, Vol. 25, 2014, pp 969-983. 
[12] Rohatgi. P.K., Guo. R.Q., Huang. P., Ray .S., "Friction and Abrasion Resistance of Cast Aluminium Alloy- Fly ash Composites", Metal. Mater. Trans. A, Vol. 28A, 2017, pp 245-250.

[13] A.P. Sannino, H.J.Rack, "Dry sliding wear of discontinuously reinforced aluminium composite: review and discussion", Wear, Vol.189, 2005, pp 1-19.

[14] Jayaram, V, \& Biswas, S K. Wear of Al2O3$\mathrm{SiC}-(\mathrm{Al}-\mathrm{Si})$ melt oxidized ceramic composites. (2009), Wear, 225-229, 1322-1326. Elsevier, United Kingdom. Composites. I. Mater. Sci., 1981, 16(4), 983.

\section{Cite this article as :}

Muzakkir Ahmed Khan, Dr. P Vijaya Kumar, Puneeth P, Meghashree K A, " Study on Mechanical Properties of Multiwalled Carbon Nanotubes Reinforced with Aluminium 2024 Matrix Composites with Nickel Coating ", International Journal of Scientific Research in Science and Technology (IJSRST), Online ISSN : 2395-602X, Print ISSN : 2395-6011, Volume 7 Issue 2, pp. 75-83, March-April 2020. Available at doi : https://doi.org/10.32628/IJSRST1207213 Journal URL : http://ijsrst.com/IJSRST1207213 